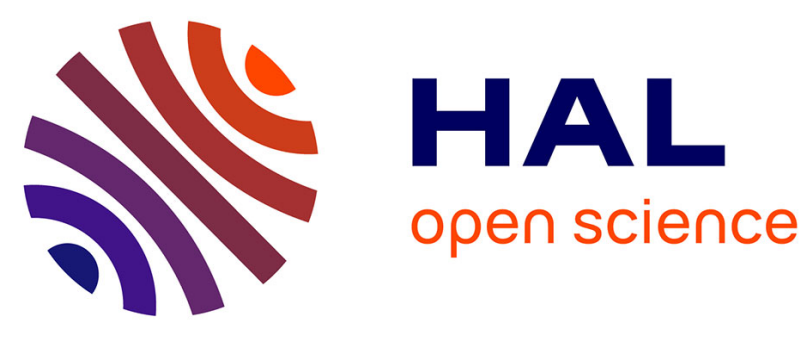

\title{
Modeling Reserve Ancillary Service as Virtual Energy Carrier in Multi-Energy Systems
}

\author{
M. Y. Damavandi, Mohsen Parsa Moghaddam, M.-R. Haghifam, M. \\ Shafie-Khah, João S. Catalão
}

\section{- To cite this version:}

M. Y. Damavandi, Mohsen Parsa Moghaddam, M.-R. Haghifam, M. Shafie-Khah, João S. Catalão. Modeling Reserve Ancillary Service as Virtual Energy Carrier in Multi-Energy Systems. 6th Doctoral Conference on Computing, Electrical and Industrial Systems (DoCEIS), Apr 2015, Costa de Caparica, Portugal. pp.431-439, 10.1007/978-3-319-16766-4_46 . hal-01343513

\section{HAL Id: hal-01343513 \\ https://hal.inria.fr/hal-01343513}

Submitted on 8 Jul 2016

HAL is a multi-disciplinary open access archive for the deposit and dissemination of scientific research documents, whether they are published or not. The documents may come from teaching and research institutions in France or abroad, or from public or private research centers.
L'archive ouverte pluridisciplinaire HAL, est destinée au dépôt et à la diffusion de documents scientifiques de niveau recherche, publiés ou non, émanant des établissements d'enseignement et de recherche français ou étrangers, des laboratoires publics ou privés.

\section{(c)(1)}

Distributed under a Creative Commons Attribution| 4.0 International License 


\title{
Modeling Reserve Ancillary Service as Virtual Energy Carrier in Multi-Energy Systems
}

\author{
M.Y. Damavandi ${ }^{1,2}$, M.P. Moghaddam ${ }^{1}$, M.-R. Haghifam ${ }^{1}$, \\ M. Shafie-khah ${ }^{2}$, and J.P.S Catalão $0^{2,3,4}$ \\ ${ }^{1}$ Tarbiat Modares University (TMU), Tehran, Iran \\ ${ }^{2}$ University of Beira Interior, Covilhã, Portugal \\ ${ }^{3}$ INESC-ID, Lisbon, Portugal. \\ ${ }^{4}$ Instituto Superior Técnico, Lisbon, Portugal, catalao@ubi.pt
}

\begin{abstract}
Multi-energy systems (MES) are considered various energy carriers and energy players in an integrated energy model. Vast amount of decision making data is gathered in these systems that cannot be processed by conventional methods. Cloud-based computing is an opportunity to develop these kinds of integrated and efficient approaches. Developing mathematical models that can be compatible with cloud-based engineering systems will help decision makers to enhance the system agendas in short to long term studies. In this paper, the energy hub approach is developed to consider electric reserve ancillary service in MES. The reserve is modeled as a virtual energy output that can be injected into the upstream network. The reserve service is defined for electric energy converters and storages, comprehensively. Therefore, the energy hub mathematical model is developed and new elements are added to the input and output vectors and system conversion matrix. For energy converters, reserve is defined as the capability of the converter to increase its output service to its maximum operational limits. Moreover, for electric storages this capability is also restricted by storages' state of charges. The numerical results demonstrate the importance of reserve considerations in MESs and allow assessing the proficiency of the proposed model.
\end{abstract}

Keywords: Energy hub model, multi-energy system, reserve ancillary service.

\section{Introduction}

Increasing the share of distributed energy resources (DER) in the energy service provision confronts policy makers with new challenges and opportunities in energy system studies. These new facilities introduce a dependency in both energy carriers and time domains [1]. Moreover, new independent decision makers enforce a high level of operational data to the energy system managers. In this situation, cloud-based engineering systems facilitate cooperation among independent decision makers and increase the utilization of inherent flexibility in the multi-energy systems (MES).

MES is an integrated energy system that considers the energy and information interaction between energy players and carriers simultaneously [2]. These interactions have been modeled by "Energy hub system" and "matrix modeling" approaches ([3] and [4]). In these models, MES is divided into some super-nodes that can interact with various energy carriers via interconnectors. Each super-node (energy hubs in energy 
hub system and distributed multi-generations in matrix modeling) consists of energy converters and energy storages, delivering the required energy service by transforming input energy carriers.

The proposed models have been developed in [5]-[7] and new considerations such as renewable energy resources, demand side management, and demand response have been included in MES's mathematical modeling. Moreover, in other power system studies, such as reliability index assessment and cascading failure mitigation, MES economic evaluation have been considered [8]-[11].

In [12] the energy hub model has been developed to consider integration of plug-in electric vehicles (PEV) in grid to vehicle $(\mathrm{G} 2 \mathrm{~V})$ modes as a manageable load for ancillary service provision (frequency control). Moreover, the capability of MES to serve ancillary services has been discussed in [13] and the new concept of multienergy/power arbitrage has been developed to consider reserve of distributed multigeneration.

In this paper, the reserve ancillary service is modeled on an energy hub approach as virtual output energy carriers that can be injected to the macro-MES level. The spinning reserve is provided from combined heat and power (CHP) units and electric storages. For CHP units, reserve provision is defined as the capability of the unit to increase its output electric power to its operational limits.

In addition, for electric storages this capability is restricted by power interaction with the system and stored energy. The energy hub model is developed to consider both storage and converter reserve provision in the mathematical model. Some rows are added to the output energy vector to model reserve energy as a virtual port, and consequently the system coupling matrix will be changed to consider the share of each energy element in the reserve provision. The numerical results demonstrate the proficiency of the proposed model and the energy scheduling adjustment of microMES in the operation time horizon.

\section{Contribution to Cloud-based Engineering Systems}

By increasing the dependency among energy carriers, conventional methods for system management are no longer effective. Thus, decision makers in the energy sector try to propose multi-dimensional models for energy systems that can cover technical, economic and environmental aspects of these systems. In this way, MES can be considered as a cloud-based engineering system consisting of various energy players and carriers.

This cloud-based perspective of the energy system increases collaboration among energy players from both energy and information points of view. Moreover, the huge amount of management data enforces energy players to develop novel computational methods to decrease system operation time and manage unwanted contingencies. The cloud-based engineering system may entail two integrated data and energy layers in such a way that energy players share information with each other for increasing their operational flexibility in both normal and contingency conditions.

In this regard, proposing standard models for system players can enable energy and information interactions among players. Since energy hub approach as a modular model has these capabilities, nowadays; researchers in energy studies try to develop new models to include more characteristics of the energy system. 
In this paper, the energy hub model is developed from a mathematical point of view to consider reserve ancillary services for a micro-MES energy player. The proposed model accelerates cooperation of the micro-MES in the cloud-based engineering system by increasing their profit from two individual energy markets. Moreover, the energy hub presentation of the reserve service as a modular approach helps system managers to exchange data among energy players more efficiently.

\section{Energy Hub Modeling}

The energy hub model consists of a conversion matrix (C) that transforms input energy carriers (p) to the required energy services (l). For assessing the impact of energy storages in MES, ref. [14] added a new vector (ن) to the input energy vector that demonstrates the changes in stored storages' state of charge (SOC). Matrix S determines the share of energy storages in the output energy vector. Moreover, one of the main energy hub approach assumptions is unidirectional energy flow. Therefore, ref. [5] has added the vector $\mathrm{k}$ in the output of the energy hub to inject the surplus energy in the system to the upstream energy network.

$$
\begin{aligned}
& {[\mathbf{C}][\mathbf{p}]=[\mathbf{l}]} \\
& {\left[\begin{array}{ll}
\mathbf{C} & \mathbf{S}
\end{array}\right]\left[\begin{array}{c}
\mathbf{p} \\
\dot{\mathbf{e}}
\end{array}\right]=[\mathbf{l}]+[\mathbf{k}]}
\end{aligned}
$$

In this paper, the electric reserve in MES is defined as the capability of MES to increase its injected electric energy to the upstream network. In the mathematical approach, this capability is considered as virtual energy output port that injected the required service to the upstream network. Therefore, new rows $\left(r^{\text {inj }}\right)$ are added to the vector $\mathrm{k}$ to determine the supplied reserve services. In addition, corresponded zero rows are added to the vector 1 .

$$
\mathbf{k}^{\text {new }}=\left[\begin{array}{c}
\mathbf{k}^{\text {old }} \\
\mathbf{r}^{\text {inj }}
\end{array}\right], \mathbf{l}^{\text {new }}=\left[\begin{array}{c}
\mathbf{l}^{\text {old }} \\
0
\end{array}\right]
$$

By adding new rows in the output, the matrices $\mathrm{C}$ and Swill be modified to determine the share of each element of the new output energy service (electric reserve).For the energy converters, the reserve service is defined as the capability of the energy converter to increase its output energy to its operational limits. Furthermore, for energy storages this capability is restricted by their output power and stored energy in each hour. Therefore, determining the reserve service for electric energy storages needs new rows in $\mathrm{p}$ to show the share of electric energy storage for serving reserve to the MES as an input virtual energy carrier $\left(\mathrm{r}^{\mathrm{St}}\right)$.

$$
\begin{gathered}
\mathbf{p}^{\text {new }}=\left[\begin{array}{c}
\mathbf{p}^{\text {old }} \\
\mathbf{r}^{\text {St }}
\end{array}\right] \\
\mathbf{C}^{\text {new }}=\left[\begin{array}{cc}
C^{\text {old }} & 0 \\
C^{\text {EC }} & C^{\text {St }}
\end{array}\right], S^{\text {new }}=\left[\begin{array}{c}
S^{\text {old }} \\
0
\end{array}\right]
\end{gathered}
$$

where:

$\mathrm{C}^{\text {old }}$ : coupling matrix that states the conversion of inputs energy carriers into outputs energy services.

$\mathrm{C}^{\mathrm{EC}}$ : coupling matrix to show the share of energy converters in output reserve which is 
based on the efficiency of energy converters.

$\mathrm{C}^{\mathrm{St}}$ : coupling matrix to show the share of storage in output reserve which is based on the discharge efficiency of storage.

$S^{\text {old }}$ : storage coupling matrix that shows the changes of output energy service versus changes in the stored energy.

M: matrix of vacant capacity of energy converters

$\mathrm{U}$ : decision making matrix with binary arrays which determines the participation of each converter in output reserve.

In order to produce $\mathrm{C}^{\mathrm{EC}}$, each array of $\mathrm{M}$ is divided by the corresponding array of $\mathrm{P}^{\text {old }}$ and after that are multiplied by array of $\mathrm{U}(6)$.

$$
\mathbf{C}^{\mathbf{E C}}=\left(\mathbf{M} / \mathbf{p}^{\text {old }}\right) \cdot \mathbf{U}
$$

By substituting the modified terms in(1), the system new equation is as (7) and (8).

$$
\begin{gathered}
{\left[\begin{array}{lc}
C^{\text {new }} & \mathbf{S}^{\text {new }}
\end{array}\right]\left[\begin{array}{c}
\mathbf{p}^{\text {new }} \\
\dot{e}
\end{array}\right]=\left[\mathbf{l}^{\text {new }}\right]+\left[k^{\text {new }}\right]} \\
{\left[\begin{array}{ccc}
C^{\text {old }} & 0 & S^{\text {old }} \\
C^{\text {EC }} & C^{\text {St }} & 0
\end{array}\right]\left[\begin{array}{c}
\mathbf{p}^{\text {old }} \\
\mathbf{r}^{\text {St }} \\
\dot{e}
\end{array}\right]=\left[\begin{array}{c}
1^{\text {old }} \\
0
\end{array}\right]+\left[\begin{array}{c}
k^{\text {old }} \\
\mathbf{r}^{\text {inj }}
\end{array}\right]}
\end{gathered}
$$

\section{MES's Operational Framework}

In this paper the MES is divided into three layers, namely as macro-MES, micro-MES and multi-energy demand (MED). Fig. 1 demonstrates a micro-MES that receives input energy carriers from macro-MES and serves required energy services to the MED. Furthermore, the micro-MES is equipped by energy converters (e.g. CHP units and auxiliary boilers (AB)) and energy storages (e.g. heat storage (HS) and electric storage (ES)). These facilities enable micro-MES to participate in both energy and ancillary service markets to increase its profit. Micro-MES operator maximizes its profit by participating in energy and reserve markets and interacting energy with MED (9).

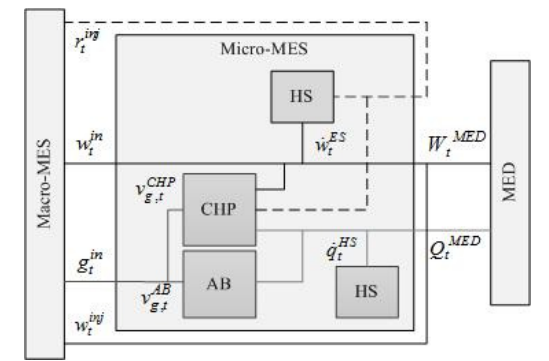

Fig.1.MES schematic considering reserve ancillary service as virtual port.

$$
\begin{aligned}
& \text { Maximizing }\left\{\sum _ { t } \left[\left(w_{t}^{i n j}-w_{t}^{i n}\right) \pi_{e, t}^{M a M E S}-g_{t}^{i n} \pi_{g, t}^{M a M E S}+r_{t}^{i n j} \pi_{r, t}^{M a M E S}+W_{t}^{M E D} \pi_{e, t}^{M E D}+\right.\right. \\
& \left.\left.Q_{t}^{M E D} \pi_{h, t}^{M E D}+r_{t}^{i n j} \rho_{r, t} \pi_{e, t}^{M a M E S}-r_{t}^{i n j} \rho_{r, t} F O R^{M E S} \pi_{e, t}^{c o n}-\left(r_{t}^{C H P} \rho_{r, t} / \eta_{e}^{C H P}\right) \pi_{g, t}^{M a M E S}\right]\right\}
\end{aligned}
$$

The operational constraints for micro-MES are described as follows: 
Input energy carrier: micro-MES energy interaction with macro-MES is restricted by the interconnectors' capability to transfer energy flow.

$$
\begin{gathered}
-\bar{W}^{i n} \leq w_{t}^{i n}-w_{t}^{i n j}-r_{t}^{i n j} \leq \bar{W}^{i n} \\
0 \leq g_{t}^{i n} \leq \bar{G}^{i n}
\end{gathered}
$$

CHP unit: The CHP unit converts input gas to the required heat and electric power. The heat and power output should be lower than units' maximum operational limits and their ratio should be equal to a predetermined parameter $\left(\lambda^{\mathrm{CHP}}\right)$.

$$
\begin{aligned}
0 \leq w_{t}^{C H P}+r_{t}^{C H P} & \leq \bar{W}^{C H P}, 0 \leq q_{t}^{C H P} \leq \bar{Q}^{C H P} \\
\lambda^{C H P} & =q_{t}^{C H P} / w_{t}^{C H P}
\end{aligned}
$$

$A B$ operational constraints: The output heat of $\mathrm{AB}$ should be lower than its operational bound.

$$
\underline{Q}^{A B} \leq q_{t}^{A B} \leq \bar{Q}^{A B}
$$

Storages interaction limit: Rate of HS and ES interactions with Micro-MES should be in its operational zone.

$$
\left|\dot{q}_{t}^{H S}\right| \leq \Gamma^{H S},\left|\dot{w}_{t}^{E S}\right| \leq \Gamma^{E S}
$$

Decision variable constraint: $v$ is dispatch factor and shows the share of each energy element of input energy and its amount should be between zero and 1 .

$$
\begin{gathered}
0 \leq v_{g, t}^{C H P}, v_{g, t}^{A B} \leq 1 \\
v_{g, t}^{C H P}+v_{g, t}^{A B}=1
\end{gathered}
$$

General energy hub conversion matrix: energy hub conversion matrix is represented in (18), transforming input energy carriers to the required energy services.

$$
\left[\begin{array}{ccccc}
1 & v_{g, t}^{C H P} \eta_{e}^{C H P} & 0 & 0 & 1 / \eta_{e}^{E S} \\
0 & v_{g, t}^{C H P} \eta_{h}^{C H P}+v_{g, t}^{A B} \eta_{h}^{A B} & 0 & 1 / \eta_{h}^{H S} & 0 \\
0 & \left.\left(\bar{G}^{i n}-v_{g, t}^{C H P} g_{t}^{i n}\right) \eta_{e}^{C H P} / g_{t}^{i n}\right) & 1 / \eta_{e}^{E S, d c h a} & 0 & 0
\end{array}\right]\left[\begin{array}{c}
w_{t}^{i n} \\
g_{t}^{i n} \\
r_{t}^{P L} \\
\dot{q}_{t}^{H S} \\
w_{t}{ }_{t}^{E S}
\end{array}\right]=\left[\begin{array}{c}
W_{t}{ }^{M E D} \\
Q_{t}^{M E D} \\
0
\end{array}\right]+\left[\begin{array}{c}
w_{t}^{i n j} \\
0 \\
r_{t}^{i n j}
\end{array}\right]
$$

\section{Numerical Results}

The micro-MES operator receives gas and electricity from macro-MES and delivers MED's required heat and electricity.

Figs. 2 and 3 depict the MED's consumption and price signals for input and output energy carriers.

Three cases are prepared to determine the operational behavior of micro-MES's elements in various system operating conditions. In cases I and II, micro-MES is equipped with $\mathrm{CHP}, \mathrm{AB}$, and ES, while in Case III the system also has a HS. 


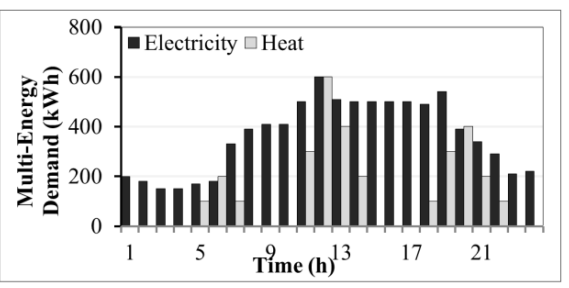

Fig.2. Electricity and heat consumption of MED.

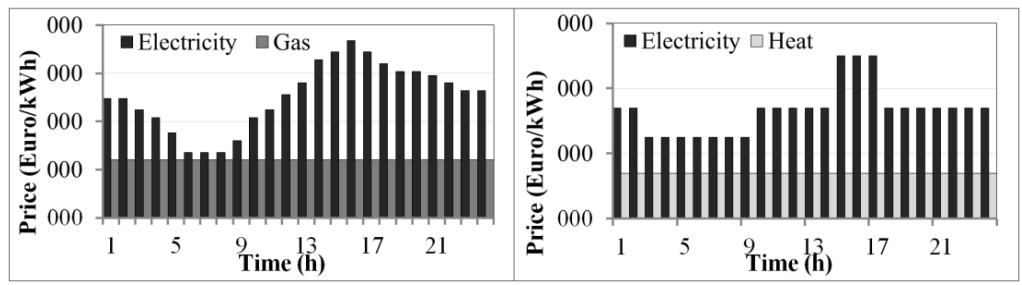

Fig.3. Left side: Input energy price. Right side: output energy price.

Case I: In this case, the micro-MES operator does not participate in the reserve ancillary service. Figs. 4 and 5 demonstrate the share of each element in electricity and heat balance of micro-MES. The CHP unit produces energy in hours 5, 11-14, and 1822, while MED consumes heat and the energy price is almost high. Moreover, ES stores energy in hours 6-8 and provides a part of electricity demand in hours 16 and 17 , when the maximum electricity price in the operation time horizon occurs.

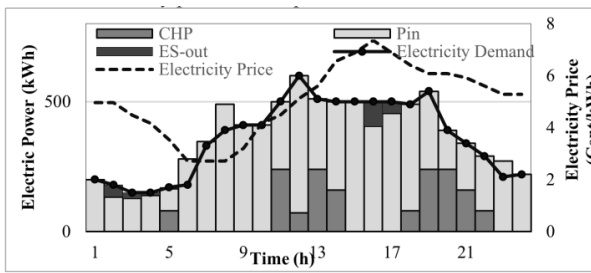

Fig.4. Electricity operation scheduling of micro-MES in Case I.

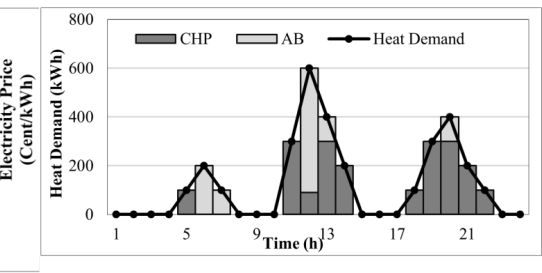

Fig.5. Heat operation scheduling of micro-MES in Case I.

Case II: In this case, besides participating in energy trade, the micro-MES sells reserve service to the macro-MES. Fig. 6 shows the CHP unit and ES reserve provision in micro-MES. In most of the operation period the ES reserve provision is restricted by its discharge rate, while for CHP unit the reserve provision restriction is more related to the share of CHP unit in electricity demand satisfaction. Moreover, Fig. 7 compares the ES behavior in Cases I and II. In Case II, ES is more eager to maintain its SOC level after hour 6 since the reserve price is acceptable for reserve provision to participate in the reserve ancillary service, instead of energy provision.

Case III: In this case, HS is added to the micro-MES's equipment. Fig. 8 depicts the share of each element in micro-MES electricity balance. The CHP unit can be operated during hours 2, 3 and 15-17 when there is no heat demand, but the surplus heat can be stored in HS. Furthermore, Fig. 9 determines that in Case III the Micro-MES prefers to 
utilize its equipment to provide energy to maximize its profit, instead of participating in the reserve service provision. It means that reserve service and HS are two sources to increase the degree of freedom of the micro-MES operator. Adding both of these resources decreases the impact of each independent source.

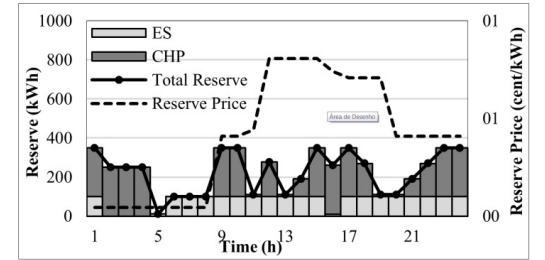

Fig.6. Reserve provision in micro-MES in Case II.

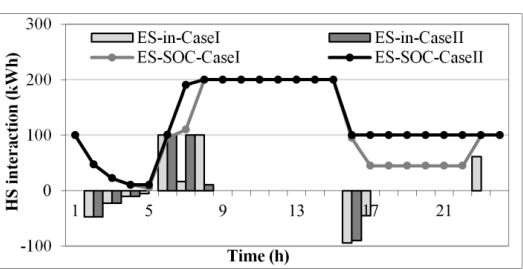

Fig.7. ES behavior in Case I and Case II.

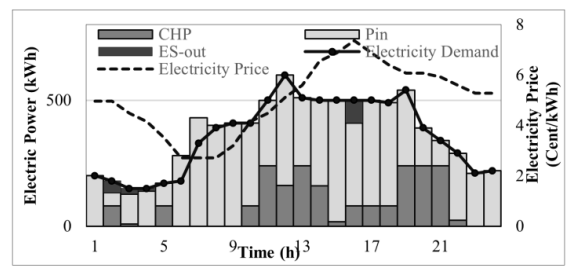

Fig. 8. Electricity operation scheduling of micro-MES in Case III.

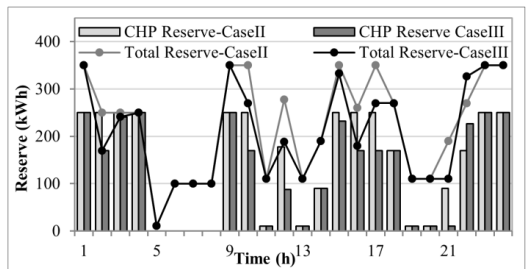

Fig. 9. CHP and total reserve provision comparisons in Case II and Case III.

\section{Conclusions}

In this paper, reserve ancillary service has been modeled in MES. The energy hub mathematical model was developed to consider reserve for both electric energy converters and storages. The numerical results have determined that the micro-MES operator for electric energy converters prefers to participate in energy trade instead of reserve operation. On the contrary, for electric storage it was more profitable for the operator to maintain its SOC to participate in reserve provision service, instead of the energy trade. As a matter of fact, ES behaves like a converter that consumes in the off peak of electricity as primary resources and delivers electricity in the peak hours of price and its operation restricted by its capacity. Therefore, it is less efficient than conventional energy converters (e.g. micro-turbines and gas engines) to produce electricity and deliver to the energy market. On the other hand, its characteristics (e.g. fast ramp) make it suitable to participate in ancillary services. Moreover, in Case III it 
was shown that each system has various sources of flexibility for the operator (e.g. storage and participation in various markets), having cross impacts that influence each other performance.

Acknowledgment. This work was supported by FEDER funds (European Union) through COMPETE and by Portuguese funds through FCT, under Projects FCOMP01-0124-FEDER-020282 (Ref. PTDC/EEA-EEL/118519/2010) and PEst$\mathrm{OE} / \mathrm{EEI} / \mathrm{LA0021/2013}$. Also, the research leading to these results has received funding from the EU Seventh Framework Programme FP7/2007-2013 under grant agreement no. 309048

\section{References}

1. P. Mancarella, "MES (multi-energy systems): An overview of concepts and evaluation models," Energy, vol. 65, pp. 1-17, 2014.

2. P. Mancarella and G. Chicco, "Real-Time Demand Response From Energy Shifting in Distributed Multi-Generation," IEEE Trans. Smart Grid, vol. 4, pp. 1928-1938, 2013.

3. M. Geidl, G. Koeppel, P. Favre-Perrod, B. Klockvl, G. Andersson and K. Frohlich, "Energy hubs for the future," IEEE Power and Energy Magazine, vol. 5, no. 1, pp.24-30, Jan.-Feb. 2007

4. G. Chicco and P. Mancarella, "Matrix modelling of small-scale trigeneration systems and application to operational optimization," Energy, vol. 34, pp. 261-273, Mar. 2009.

5. M. Schulze, L. Friedrich, and M. Gautschi, "Modeling and optimization of renewables: applying the Energy Hub approach," in Proc. ICSET Conf., 2008.

6. F. Kienzle, Ahc, x030C, P. in, and G. Andersson, "Valuing Investments in Multi-Energy Conversion, Storage, and Demand-Side Management Systems Under Uncertainty," IEEE Trans. Sustainable Energy, vol. 2, pp. 194-202, 2011.

7. P. Mancarella and G. Chicco, "Real-Time Demand Response From Energy Shifting in Distributed Multi-Generation," IEEE Trans. Smart Grid, vol. 4, pp. 1928-1938, 2013.

8. M. C. Bozchalui, S. A. Hashmi, H. Hassen, C. A. Canizares, and K. Bhattacharya, "Optimal Operation of Residential Energy Hubs in Smart Grids," Smart Grid, IEEE Transactions on, vol. 3, pp. 1755-1766, 2012.

9. M. Houwing, R. R. Negenborn, and B. De Schutter, "Demand Response with Micro-CHP Systems," Proceedings of the IEEE, vol.99, no.1, pp.200-213, Jan. 2011

10.M.Almassalkhi and I. Hiskens, "Impact of energy storage on cascade mitigation in multienergy systems," Proc. IEEE Power and Energy Society General Meeting, San Diego, Jul. 2012, pp. 1-8.

11.M.R. Haghifam and M. Manbachi, "Reliability and availability modeling of combined heat and power (CHP) systems," International Journal of Electrical Power \& Energy Systems, vol. 33, no. 3, pp. 385-393, Mar. 2011

12.M. D. Galus, S. Koch, and G. Andersson, "Provision of Load Frequency Control by PHEVs, Controllable Loads, and a Cogeneration Unit," IEEE Trans. Industrial Electronics, vol. 58, pp. 4568-4582, 2011.

13.P. Mancarella and G. Chicco, "Integrated energy and ancillary services provision in multienergy systems," in Proc. IREP Symposium, 2013.

14.F. Adamek, M. Arnold, and G. Andersson, "On Decisive Storage Parameters for Minimizing Energy Supply Costs in Multicarrier Energy Systems," IEEE Trans. Sustainable Energy, vol. 5, pp. 102-109, 2014. 